\title{
Inauguration of CAAT-EU - a memorable start to a transatlantic collaboration
}

University of Konstanz, 30 ${ }^{\text {th }}$ March 2010

The Center for Alternatives to Animal Testing-Europe (CAATEU) is a joint venture of the Johns Hopkins University in Baltimore, USA, and the University of Konstanz in Germany. It was created as a communication platform for science, industry, regulatory authorities, and animal welfare organizations in Europe and the US. This transatlantic venture will promote the application and teaching of humane science, raise funds from industrial and private sponsors for this purpose, and participate in and/or coordinate EU-funded projects. Working together, CAAT and CAAT-EU promise sound scientific synergy involving experts from both sides of Atlantic to promote the implementation of human-relevant alternative approaches, the advancement of research in this field, and the dissemination of the 3 Rs

The inaugural ceremony took place on March $30^{\text {th }} 2010$ in the Senate Hall of the University of Konstanz. In addition to the directors of CAAT and CAAT-EU, the list of speakers included University representatives, cooperation partners, supporters from industry and science, and the animal welfare organization Eurogroup for Animals, as well as the three designated "Patrons of alternative methods."

The Senate Hall was packed with 120 guests. The mild weather and views of snow-capped Alps and sparkling Lake Constance provided a memorable atmosphere. Ulrich Ruediger, the rector of the University of Konstanz, gave the welcome speech, which described the university's focus on Life Sciences. He was followed by Thomas Hartung, director of CAAT, co-director of CAAT-EU, and professor at both universities, who initiated of the formation of CAAT-EU. His talk offered an introduction to the US concept of a "Toxicology for the $21^{\text {st }}$ century" (Tox-21c), which has stirred tremendous interest and excitement in the field. Hartung introduced the rationale for human-relevant alternative methods and explained the inadequacies of the initial calculations carried out for REACH. Hartung quoted Francis Collins, now director of the NIH: "We propose a shift from primarily in vivo animal studies to in vitro assays, in vivo assays with lower organisms, and computational modeling for toxicity assessments ... (Toxicity testing) was expensive, time-consuming, used animals in large numbers, and didn't always work." Michael Klag, Dean of Johns Hopkins Bloomberg School of Public Health, discussed the significance of public health in the US, emphasizing the role of the Johns Hopkins Bloomberg School in medical research and also in funding of international research and aid programs.

Alan Goldberg, former director of CAAT and chairman of the CAAT board, used the example of the Draize Test on rabbit eyes to demonstrate the advantages of in vitro methods and the inaccuracy of animal models. As one of the "patrons of alternative methods in the life sciences" appointed by the 2009 World Congress on Alternative Methods in Rome, he gave an insider's overview of the success story CAAT's push for alternatives over the last three decades. He stressed the necessity and importance of in vitro toxicology and the role of transatlantic cooperation.

Marcel Leist, director of CAAT-EU and DoerenkampZbinden chair for in vitro toxicology and biomedicine at the University of Konstanz, detailed the scope and functions of CAAT-EU: 1) coordination of research consortia; 2) installa- 
tion of a dynamic CAAT-EU faculty and advisory board to address topical issues; 3) organization of information days on relevant developments in the US and Europe; 4) strategic project development; and 5) joint education programs. Moreover, he outlined plans for the Transatlantic Think Tank of Toxicology $\left(\mathrm{t}^{4}\right)$.

Both universities participating in the CAAT-EU venture have a history of collaboration, as Gerd Gantefoer, professor of physics in Konstanz and research professor at Johns Hopkins explained in a lively and informative talk. He described the difficulties but also the value of his experiences collaborating in a joint research project on nanomaterials for energy storage and energy conversion.

Michael Balls, emeritus Professor for Medical Cell Biology at the University of Nottingham, trustee of the Fund for the Replacement of Animals in Medical Experiments (FRAME), Editor of ATLA, and a second patron of alternative methods, was one of the highlights of the ceremony with his speech, "Alternative methods, servant to two masters." Balls advised CAAT-EU to be aware of conflicts of interest, to compete by putting forward new ideas, to collaborate in putting the most innovative concepts into practice, to join in leading the "revolution," and to contribute to the improvement of hazard prediction and risk assessment by developing, validating, and employing advanced methods and replacing the use of flawed animal tests.

Horst Spielmann, retired head of the National German Centre for the Documentation and Evaluation of Alternatives to Animal Testing (ZEBET) and professor for regulatory risk assessment at the Free University of Berlin, and the third patron of alternative methods, presented his vision of the future of developmental toxicology. Spielmann spoke of the need for harmonization of reproductive toxicity testing across all sectors of regulatory testing, of exposure-driven testing of industrial chemicals, the implementation of a new "extended one-generation reproductive toxicity study" and other in vitro methods for toxicity testing in the $21^{\text {st }}$ century. As examples, he pointed to the ReProTect in vitro battery and the embryonic stem cell technology focusing on molecular endpoints in both the murine and human stem cell test.

Congratulatory greetings from sponsors, supporters, and partners rounded out the inaugural festivities. Adela Lopez De Cerain, president of ECOPA, discussed the structure of the European Consensus Platform. The participating National Consensus Platforms are Austria (ZET), Czech Republic (CZECOPA), The Netherlands (ZonMw), France (within Inserm), Germany (SET), Hungary (HUCOPA), Italy (IPAM), Spain (REMA), Belgium (BPAM), Denmark (DACOPA), Fin- land (FINCOPA), Norway (NORECOPA), Sweden (SWECOPA), Switzerland (3Rs Research Foundation), and Poland (POLCOPA).

Kirsty Reid, policy officer for research animals of EuroGroup for Animals, gave an overview of the activities of European organizations working in the $3 \mathrm{Rs}$. She stressed that a paradigm shift is needed to accomplish scientific improvements and safety testing without the reliance on animals and with more emphasis on the research, implementation, and enforcement of 3Rs.

Franz P. Gruber, president of the Doerenkamp-Zbinden Foundation (DZF), described the establishment of the foundation 25 years ago and its activities and continuing support of alternative methods to animal experimentation in biomedical research and education. The foundation, in recognition of the importance of academic research, has established six academic chairs in Germany, Switzerland, USA, the Netherlands and India, and is supporting CAAT and CAAT-EU. Gruber spoke enthusiastically about the University of Konstanz, with its 20-year tradition of research on alternative methods and the unique scientific focus of the Faculty of Biology, as the ideal place for the installation of CAAT-EU.

Robert Landsiedel, head of acute toxicity, experimental toxicity and ecology at BASF, discussed his organization's application of alternative methods. He reported that 20 alternative methods are currently in use at BASF, with $35 \%$ of all toxicological studies performed using alternative methods. The first lab converted for exclusive use of alternative methods has been installed. BASF has also developed a screening strategy for agrochemicals and alternative testing strategies for cosmetic ingredients, and sponsors CAAT-EU.

Didma de Groot, Senior Scientist in neurotoxicology and safety pharmacology at TNO, Zeist, The Netherlands, explained why TNO adopted alternative methods years ago. She stressed the need for sustainable testing approaches that contribute to the $3 \mathrm{Rs}$, are more predictive for humans, less laborious, and faster than current methods..

After the official signing of the contract between the universities by Ulrich Ruediger and Michael Klag, the inauguration ended with a reception and a festive dinner at the Inselhotel in Konstanz.

The festive inauguration marks the starting point of the first transatlantic organization for alternatives. Fostering a dialogue and promoting conceptual work to reduce animal testing in safety assessments, agent discovery, and research is a global challenge that calls for in-depth collaboration. The caravan to 3Rs and Tox-21c now has a new CAATalyzer.

Mardas Daneshian 